\title{
A Systematic Literature Review on the Product Ranking Methods
}

\author{
Achmad Choirun Najib, Nur Aini Rakhmawati \\ Information Systems Department \\ Institut Teknologi Sepuluh November \\ ahmadchoirunnajib@gmail.com
}

\begin{abstract}
The vast amount of online products data such as product properties, or product reviews plays an essential role in providing better information to the consumers to make a purchase decision. Thus, product ranking is a valuable research topic while many methods proposed by researchers in different approaches and case studies. This paper aims to develop a Systematic Literature Review (SLR) to summarise existing research and finding new gaps in product ranking research. We develop SLR by defining inclusion criteria, initiating preliminary findings, selecting primary studies and summarizing the outcome of results. We proposed three dimensions as research questions. It consists of ranking item types of product ranking, approaches of product ranking and dataset characteristics of each study. First, we found three ranking item types of product ranking that indicate what will be ranked in the studies. It consists of product ranking, aspect ranking, and review ranking. Second, there are four approaches, namely: collaborative filtering, content-based recommendation, hybrid-based and knowledge-based. Third, datasets characteristics summarise the information of datasets like the type of data and statistics. Also, we found new gaps by identifying each dimension to positioning for further research in the future.
\end{abstract}

Keywords: a systematic review, aspect ranking, product ranking, ranking methods, review ranking

\section{Introduction}

Online shopping is becoming increasingly popular and important that used by seller and buyer to make transactions over the Internet. The huge of users increase the amount of online products data include product properties or product reviews. It plays an essential role in providing better information to a consumer to make a purchase decision. Usually, consumers using sales history, numeric rating, product reviews, and product aspects as a consideration before making a purchase decision. However, it is difficult for consumers to read all product reviews and find product aspects in text reviews. Hence, product ranking plays a vital role to make better and faster consumers purchase decision to buy a desirable product.

Product ranking provides benefits for both consumers and firms. At the consumer's side, good product ranking improves the consumers shopping experience. On the other hand, firms can perform analysis to get customer perception and improvements regarding their products based on product reviews or market feedback. Sorokina et al. [1] improving relevance ranking influence the shopping experience of millions of consumers and significantly impact revenue at Amazon e-commerce.
Many studies perform product ranking using various approach and case studies. Huang et al., Alengadan et al., Liu et al., Kumar et al., Najmi et al. [2]-[6] employ product reviews (e.g., numeric rating, text reviews) using sentiment analysis to perform product ranking. Alengadan et al. [3] perform product ranking using product aspects to gear up faster decision-making. Krestel et al. [7] employ numeric rating, sentiment analysis, language model, topic model to perform review ranking. Sangeetha et al. employs aspect extraction using pos tagging and ranking the aspects using sentiment score which uses sentiment dictionaries. Usually, every different case study implies a different approach to present appropriate product ranking. It may cause new gaps for particular domain or case study.

For a specific area, e.g., graph, knowledge base, and semantic web require a different approach to serving appropriate product ranking. Scholz et al. [8] perform product ranking using a graph model with product centrality ranking algorithm (PCRA), which solves some problems of existing default ranking algorithms. The PCRA uses the PageRank centrality of products in a product domination graph to determine their ranks.

Although many studies had developed on product ranking research, to the best of our knowledge, no one 
develops a systematic literature review to summarise existing product ranking methods and find new gaps for positioning further research in the future. Therefore, we perform systematic literature. Our main contribution can be listed as follows:

- Presents summaries of product ranking methods

- Finding new gaps in positioning for further research in the future

We present research method in section 2. Section 3 describes our results. Section 4 describes discussion and close with conclusions in Section 5.

\section{Research Methods}

\section{a. Research Questions}

A systematic literature review is a method for identifying, evaluating and interpreting all available researches relevant to a particular research question, or topic area, or phenomenon of interest. It can be used to summarise existing research, finding new gaps in a specific topic of study and positioning for new research [9].

In this paper, we present the results of a systematic literature review on the product ranking methods. The position of this paper is in the Information Retrieval field. We study the following research questions :

1. What are the existing ranking items for product ranking?

2. What are the current approaches for product ranking?

3. What are datasets characteristics for ranking a list of products?

At first, we define existing ranking items as a research question to know the parameters that may contribute to perform product ranking. These parameters can be accumulated as a weight to present the better ranking result at product ranking approach. Second, the current approaches show how to conduct product ranking. For each product ranking approach has a different method to rank the items at the dataset. Third, the characteristics of the datasets show how appropriate method performs at the right dataset characteristic. Finally, these research questions aim to produce a summary of product ranking methods that can be used to perform and present better product ranking approaches and results in future research.

\section{b. Research Process}

The research process consisted of three main steps. The first step is defining inclusion criteria, the second step is preliminary searches, and the third step is to study selection.

\section{1) Defining Inclusion Criteria}

Based on the focus topic of research, we set four types of inclusion criteria to align our inclusion/exclusion criteria related to product ranking: product ranking, aspect ranking, review ranking and empirical. Table 1 lists the types and detail the examples of the relevant or non-relevant topic.

\section{2) Preliminary Findings}

We were initially selecting and identifying primary studies. We make an initial search to select, develop and evaluate strings or keywords. We use "product ranking", "product ranking methods", "aspect ranking" and "review ranking" strings, to find the relevant papers. The results show many studies for this topic, only the relevant papers selected by criteria as candidate studies. We identified from the title and keywords.

\section{3) Study Selection}

The set of relevant papers as primary studies candidate identified by filtering based on abstract and full text. Abstract filtering was performed by ensuring candidates must be specified standard abstract sections such as background, purpose, methods, and results. Full-text filtering was performed by evaluating the text of each candidate against the four types of inclusion criteria.

\section{c. Finding Results}

At the preliminary findings, we found eight candidate studies at Elsevier, 16 at IEEE, four at Springer, one at ACM and three at other publishers. After study selection, we eliminated by evaluating abstract and ensuring the full text satisfy to our inclusion criteria. Only seven studies at Elsevier, nine studies at IEEE, four studies at Springer, one study at ACM, and one study at another publisher were selected as primary studies. Total we found 22 primary studies. We summarise each primary studies based on year, publishers, publication types and brief aim. Year, publishers and publication types fields figured in Fig. 1-3. Table 2 summarises title, author, year, publisher, publication type and brief aim of each primary study.

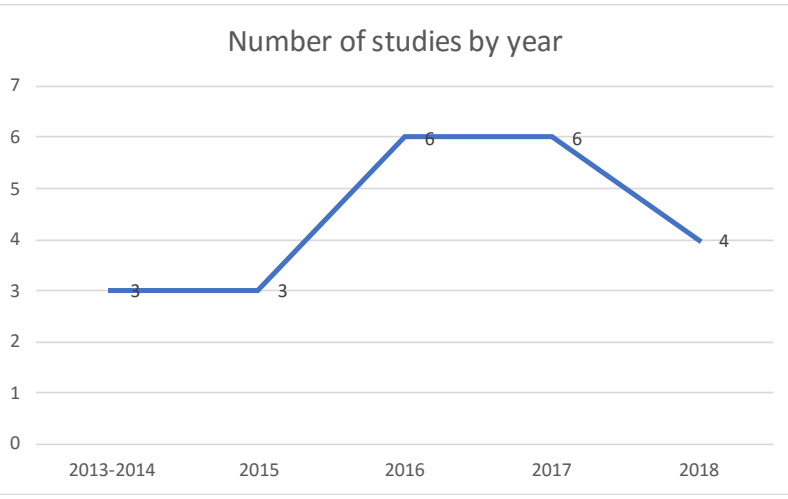

Figure 1. Number of studies by year 
Number of studies by publisher

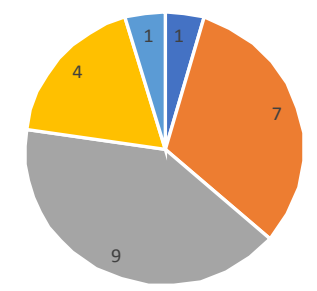

- ACM - Elsevier - IEEE $=$ Springer $=$ Other

Figure 2. Number of studies by the publisher

Number of studies by publication type

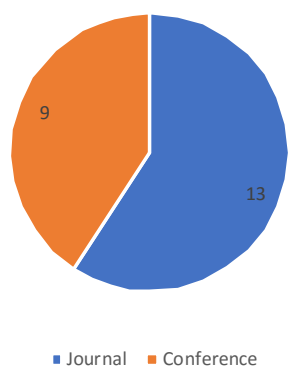

Figure 3. Number of studies by publication type

Table 1. List of Types and Detail Examples of Relevant and Non-relevant Topic

\begin{tabular}{lll}
\hline \multicolumn{1}{c}{ Type } & \multicolumn{1}{c}{ Relevant } & \multicolumn{1}{c}{ Non-relevant Examples } \\
\hline $\begin{array}{l}\text { Product } \\
\text { Ranking }\end{array}$ & $\begin{array}{l}\text { Presents methods to rank products based } \\
\text { on specific criteria; product ranking on } \\
\text { search or recommendation list }\end{array}$ & $\begin{array}{l}\text { Ranking model for product name extraction; } \\
\text { brand ranking }\end{array}$ \\
Aspect Ranking & $\begin{array}{l}\text { Presents methods to find aspects of a } \\
\text { product and rank these aspects }\end{array}$ & $\begin{array}{l}\text { Presents methods to find aspects of a product } \\
\text { only }\end{array}$ \\
Review Ranking & $\begin{array}{l}\text { Presents methods to rank reviews of a } \\
\text { product based on specific criteria }\end{array}$ & Review classification \\
Empirical & $\begin{array}{l}\text { Based on the case study, experimental } \\
\text { reports, research article }\end{array}$ & $\begin{array}{l}\text { Systematic review, textbooks, student } \\
\text { experiments, theory papers }\end{array}$ \\
\hline
\end{tabular}

Table 2. Summary of Primary Studies

\begin{tabular}{|c|c|c|c|c|}
\hline Code & Author, Year & $\begin{array}{l}\text { Publisher, } \\
\text { Publication } \\
\text { type }\end{array}$ & Title & Brief aim \\
\hline P1 & $\begin{array}{l}\text { Sorokina, et al. } \\
2016[1]\end{array}$ & $\begin{array}{c}\text { ACM, } \\
\text { Conference }\end{array}$ & $\begin{array}{l}\text { Amazon Search: The Joy of Ranking } \\
\text { Products }\end{array}$ & $\begin{array}{l}\text { Explain several algorithms used in Amazon } \\
\text { Search today }\end{array}$ \\
\hline P2 & $\begin{array}{l}\text { Zhang et al., } \\
2015 \text { [10] }\end{array}$ & $\begin{array}{l}\text { Elsevier, } \\
\text { Journal }\end{array}$ & $\begin{array}{l}\text { Prediction uncertainty in collaborative } \\
\text { filtering: Enhancing personalized } \\
\text { online product ranking }\end{array}$ & $\begin{array}{l}\text { Propose RPU (Ranking with Prediction Uncertainly) } \\
\text { methods to improve the accuracy of personalized } \\
\text { product ranking through incorporating the uncertainty } \\
\text { information }\end{array}$ \\
\hline
\end{tabular}




\begin{tabular}{|c|c|c|c|c|}
\hline Code & Author, Year & $\begin{array}{l}\text { Publisher, } \\
\text { Publication } \\
\text { type }\end{array}$ & Title & Brief aim \\
\hline P3 & $\begin{array}{l}\text { Krestel et al., } \\
2015[11]\end{array}$ & $\begin{array}{l}\text { Elsevier, } \\
\text { Journal }\end{array}$ & Diversifying customer review rankings & $\begin{array}{l}\text { Present a framework to rank product reviews by } \\
\text { optimizing the coverage of the ranking concerning } \\
\text { sentiment or aspects, or by summarizing all reviews with } \\
\text { the top-K reviews in the ranking }\end{array}$ \\
\hline P4 & $\begin{array}{l}\text { Yang et al., } 2016 \\
{[12]}\end{array}$ & $\begin{array}{l}\text { Elsevier, } \\
\text { Journal }\end{array}$ & $\begin{array}{l}\text { Integrating rich and heterogeneous } \\
\text { information to design a ranking } \\
\text { system for multiple products }\end{array}$ & $\begin{array}{l}\text { Propose a method to integrate heterogeneous } \\
\text { information (descriptive and comparative information). } \\
\text { Help consumers to compare multiple products and make } \\
\text { appropriate purchase decisions effortlessly }\end{array}$ \\
\hline P5 & $\begin{array}{l}\text { Liu et al., } 2017 \\
{[4]}\end{array}$ & $\begin{array}{l}\text { Elsevier, } \\
\text { Journal }\end{array}$ & $\begin{array}{l}\text { Ranking products through online } \\
\text { reviews: A method based on } \\
\text { sentiment analysis technique and } \\
\text { intuitionistic fuzzy set theory }\end{array}$ & $\begin{array}{l}\text { Propose an approach based on the sentiment analysis } \\
\text { technique and the intuitionistic fuzzy set theory to rank } \\
\text { the products through online reviews. }\end{array}$ \\
\hline P6 & $\begin{array}{l}\text { Scholz et al., } \\
2017[8]\end{array}$ & $\begin{array}{l}\text { Elsevier, } \\
\text { Journal }\end{array}$ & $\begin{array}{l}\text { Using PageRank for non-personalized } \\
\text { default rankings in dynamic markets }\end{array}$ & $\begin{array}{l}\text { Propose a method utilizing the product centrality } \\
\text { ranking algorithm (PCRA), which solves some problems } \\
\text { of existing default ranking algorithms. The PCRA } \\
\text { uses the PageRank centrality of products in a product } \\
\text { domination graph to determine their ranks }\end{array}$ \\
\hline $\mathrm{P} 7$ & $\begin{array}{l}\text { Sabharwal et al., } \\
2017[13]\end{array}$ & $\begin{array}{l}\text { Elsevier, } \\
\text { Journal }\end{array}$ & $\begin{array}{l}\text { An SVD-Entropy and Bilinearity } \\
\text { based product ranking algorithm } \\
\text { using heterogeneous data }\end{array}$ & $\begin{array}{l}\text { Review some of the prevalent review classification } \\
\text { techniques and present a hybrid approach, involving } \\
\text { Singular Value Decomposition (SVD), Entropy and } \\
\text { Bilinear Similarity measures, that uses heterogeneous } \\
\text { product data and simultaneously analyze and rank } \\
\text { products for customers }\end{array}$ \\
\hline P8 & $\begin{array}{l}\text { Kumar et al., } \\
2018[5]\end{array}$ & $\begin{array}{l}\text { Elsevier, } \\
\text { Journal }\end{array}$ & $\begin{array}{l}\text { Aspect-based opinion ranking } \\
\text { framework for product reviews using a } \\
\text { Spearman's rank correlation coefficient } \\
\text { method }\end{array}$ & $\begin{array}{l}\text { Propose a new framework for ranking products based } \\
\text { on product aspects using Spearman's rank correlation } \\
\text { coefficient }\end{array}$ \\
\hline P9 & $\begin{array}{l}\text { Kaur et al., } 2016 \\
{[14]}\end{array}$ & $\begin{array}{c}\text { FCS } \\
\text { (Foundation } \\
\text { of Computer } \\
\text { Science), } \\
\text { Journal } \\
\end{array}$ & $\begin{array}{l}\text { Semantic Product Ranking Model } \\
\text { (SePRaM) using PNN over the } \\
\text { Heuristic Product Data }\end{array}$ & $\begin{array}{l}\text { Propose a model based upon the hybridized approach } \\
\text { using dual-stage rank preparation. First stage using } \\
\text { content-based ranking and the second is collaborative } \\
\text { filtering }\end{array}$ \\
\hline $\mathrm{P} 10$ & $\begin{array}{l}\text { Huang et al., } \\
2013[2]\end{array}$ & $\begin{array}{c}\text { IEEE, } \\
\text { Conference }\end{array}$ & $\begin{array}{l}\text { Web Product Ranking Using Opinion } \\
\text { Mining }\end{array}$ & $\begin{array}{l}\text { Presents a product ranking system using opinion mining } \\
\text { techniques }\end{array}$ \\
\hline $\mathrm{P} 11$ & $\begin{array}{l}\text { Zha et al., } 2014 \\
{[15]}\end{array}$ & IEEE, Journal & $\begin{array}{l}\text { Product Aspect Ranking and Its } \\
\text { Applications }\end{array}$ & $\begin{array}{l}\text { Propose product aspect ranking framework, which } \\
\text { automatically identifies the important aspects of } \\
\text { products from online consumer reviews, aiming at } \\
\text { improving the usability of the numerous reviews }\end{array}$ \\
\hline P12 & $\begin{array}{l}\text { Raja et al., } 2014 \\
{[16]}\end{array}$ & $\begin{array}{c}\text { IEEE, } \\
\text { Conference }\end{array}$ & $\begin{array}{l}\text { ProRankSys: Ranking consumer } \\
\text { products by predicting opinion's } \\
\text { weight on reviews }\end{array}$ & $\begin{array}{l}\text { Propose a method to calculate individual opinion's } \\
\text { weight by predicting the strength of each review and } \\
\text { assessing the overall rank of the product by consolidating } \\
\text { the predicted review strength }\end{array}$ \\
\hline P13 & $\begin{array}{l}\text { Bhamre et al., } \\
2016[17]\end{array}$ & $\begin{array}{l}\text { IEEE, } \\
\text { Conference }\end{array}$ & $\begin{array}{l}\text { Aspect Rating Analysis Based Product } \\
\text { Ranking }\end{array}$ & $\begin{array}{l}\text { Propose a system use of aspect rating to improve the } \\
\text { performance of important aspect identification and } \\
\text { ranking }\end{array}$ \\
\hline P14 & $\begin{array}{l}\text { Alrababah et al., } \\
2016[18]\end{array}$ & $\begin{array}{c}\text { IEEE, } \\
\text { Conference }\end{array}$ & $\begin{array}{l}\text { Product aspect ranking using } \\
\text { sentiment analysis and TOPSIS }\end{array}$ & $\begin{array}{l}\text { Propose aspect ranking framework using sentiment } \\
\text { analysis and TOPSIS (Technique for Order Performance } \\
\text { by Similarity to Ideal Solution) }\end{array}$ \\
\hline P15 & $\begin{array}{l}\text { Sangeetha et al., } \\
2017 \text { [19] }\end{array}$ & $\begin{array}{c}\text { IEEE, } \\
\text { Conference }\end{array}$ & $\begin{array}{l}\text { Aspects based Opinion Mining } \\
\text { from Online Reviews for Product } \\
\text { Recommendation }\end{array}$ & $\begin{array}{l}\text { Propose a method for identifying and prioritizing the } \\
\text { aspects of products based on the online reviews given by } \\
\text { the customers using aspect extraction and scoring aspects } \\
\text { using sentiment dictionaries }\end{array}$ \\
\hline
\end{tabular}




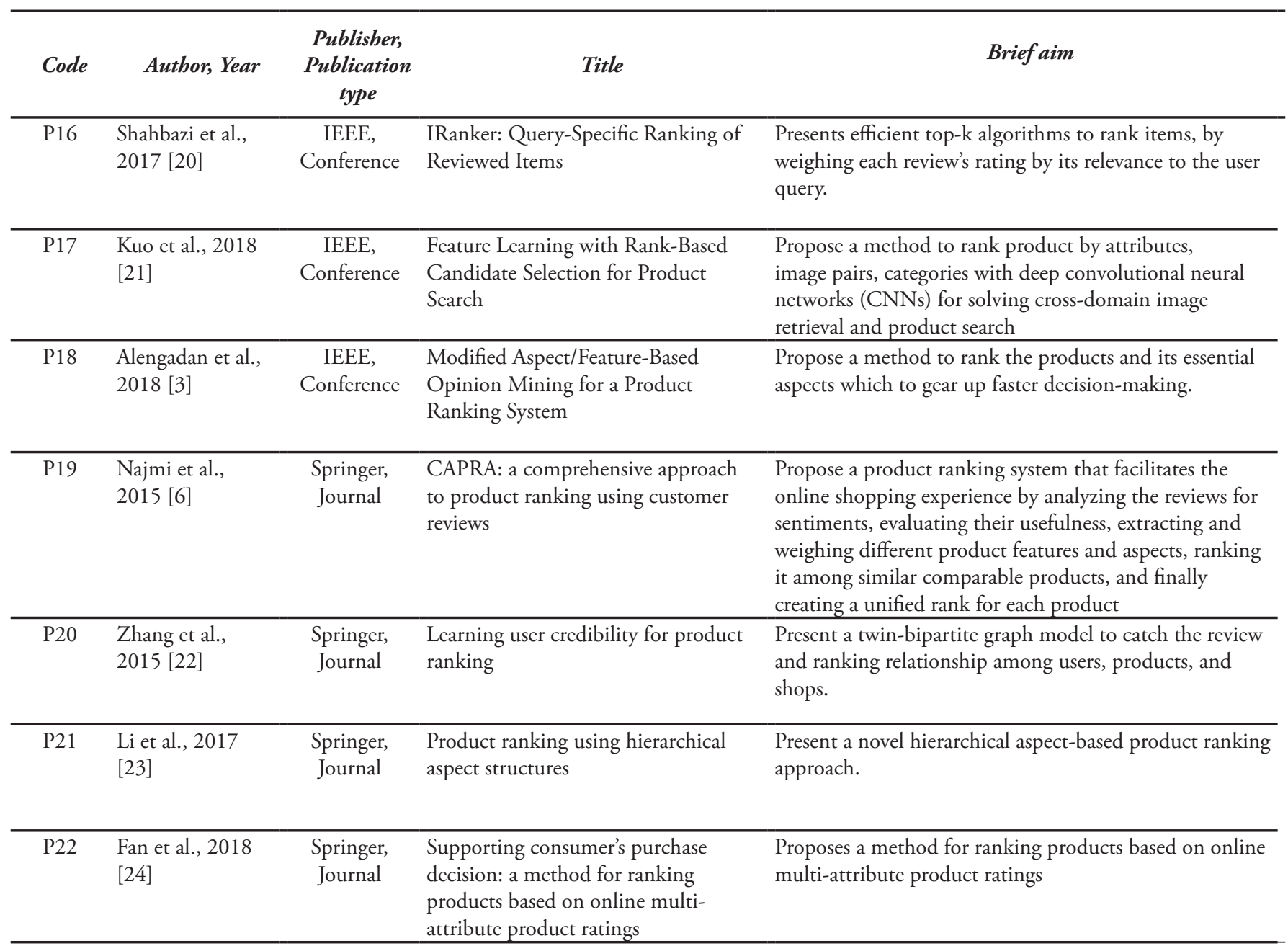

\section{Results}

In this section, we present our findings. We discuss the findings organized according to our research questions.

\section{a. Ranking Items}

In this section, we answer our first research question, RQ1. What are the existing ranking items for product ranking? Primary studies generally proposed product ranking method to rank three ranking items consist of product ranking, review ranking and aspect ranking. We found 17 studies propose methods to perform product ranking, one study proposes a method to perform review ranking, four studies propose methods to perform aspect ranking. We organized the found primary studies based on three ranking items in Table 3.

Table 3. Primary studies categorized by ranking items

\begin{tabular}{clc}
\hline $\begin{array}{c}\text { Ranking } \\
\text { item }\end{array}$ & \multicolumn{1}{c}{ Primary studies } & Total \\
\hline \multirow{2}{*}{ Product } & P1, P2, P4, P5, P6, P7, P8, P9, P10, & \\
& P12, P16, P17, P18, P19, P20, P21, & 17 \\
Review & P2 & 1 \\
Aspect & P11, P13, P14, P15 & 4 \\
\hline
\end{tabular}

\section{1) Product Ranking}

Product ranking performs the comparison between the list of product items to specify the position of the item. It aims to serve appropriate product ranking to improve consumers experience and to expedite consumers purchase decision. It was done by various ranking approaches based on a custom algorithm or specific criteria in a ranking system. Huang et al., Alengadan et al., Liu et al., Kumar et al., Najmi et al. [2]-[6] employ product reviews (e.g., numeric rating, text reviews) using sentiment analysis to perform product ranking. Alengadan et al. [3] using product aspects to perform product ranking to gear up faster decision-making. Thus, review ranking and aspect ranking becoming part of product ranking.

2) Review Ranking

Product reviews must be ranked based on the importance of each text review to serve a better purchase decision to the consumers. The importance of a review frequently indicated by the recency and helpfulness of the review and calculated by specific ranking criteria. Krestel et al. [7] employ numeric rating, sentiment analysis, language model, topic model to perform review ranking. This study proposes three review ranking strategies consist of summary-focused ranking, sentiment-focused 
ranking, and topic-focused ranking. Summaryfocused summarises the opinions about a product present in all reviews. Sentiment-focused summarise only one particular class of ratings, for example, negative aspects as represented by the topic-rating model with score one. Topic-focused focus the review ranking on a specific latent topic and allows to get all opinions - positive, neutral, and negative - about a particular aspect

3) Aspect Ranking

Consumers frequently consider the aspects of a product before purchasing a product. It aims to find the importance of aspects. The importance of aspects may consist of quality, performance, durability or other measurements. Hence, it is essential to rank aspects of a product to identify the critical aspects of products from online consumer reviews, aiming at improving the usability of the numerous reviews. Commonly, aspect ranking was done by extracting aspects and ranked these aspects using sentiment analysis based on text reviews. Sangeetha et al. [19] employ aspect extraction using pos tagging and rank the aspects using sentiment score which utilizes sentiment dictionaries.

\section{b. Ranking Approaches}

In this section, we answer our second research question, RQ2. What are the current approaches for product ranking? We classified the found primary study approaches to four ranking approach types consist of collaborative filtering, content-based, hybrid-based, knowledge-based [14]. We found one study conduct collaborative filtering approach, 20 studies conduct a content-based approach, and one study conduct hybrid and knowledge approach to perform product ranking. We organized primary studies based on the ranking method in Table 4.

Table 4. Primary studies classified by ranking approach

\begin{tabular}{llc}
\hline Ranking item & \multicolumn{1}{c}{ Primary studies } & Total \\
\hline $\begin{array}{l}\text { Collaborative } \\
\text { filtering }\end{array}$ & P2 & 1 \\
& P3, P4, P5, P6, P7, P8, P9, P10, & \\
Content-based & P11, P12, P13, P14, P15, P16, & 20 \\
& P17, P18, P19, P20, P21, P22 & \\
$\begin{array}{l}\text { Hybrid based } \\
\begin{array}{l}\text { Knowledge- } \\
\text { based }\end{array}\end{array}$ & P1 & 1 \\
\hline
\end{tabular}

1) Collaborative filtering approach

Collaborative filtering approach ranking conducted by using a collaborative filtering algorithm. Collaborative filtering is a method to perform automatic predictions based on information or preferences gathered from many users data [25]. A typical example is movie recommendation might be like for a new user. Zhang et al. [10] conduct product ranking using a collaborative filtering approach in MovieLens dataset. This study proposes a method called RPU (Ranking with Prediction Uncertainly) to improve the accuracy of personalized product ranking through incorporating the uncertainty information. This study utilizes historical data, e.g., consumer, item and rating to perform collaborative filtering and product ranking.

2) Content-based approach

Content-based approach ranking conducted by using the concepts of information retrieval and information filtering, e.g., string similarity, document similarity, TF-IDF measurement [14]. In majority, products ranked by utilizing the product data, e.g., product title, description, sales history, or product reviews. Twenty primary studies use a content-based approach to perform ranking by utilizing text information such as text review, numeric rating, number of voting, product images and product history data. They ranked by various methods, e.g., custom weighting, graph weighting, sentiment analysis, and PageRank. Except in one study, Kuo et al. [21] using an image as a query to present similar images as product ranking results. It was done by using convolutional neural networks. Table 5 summarises the content-based approach studies ranking methods.

3) Hybrid-based approach

Hybrid-based approach ranking used a combination of two or more techniques. It aims to generate a better and appropriate ranking. Combine collaborative filtering, and content-based approach produces more accurate recommendation and ranking [14]. Sorokina et al. [1] perform product ranking on Amazon e-commerce using various methods, e.g., general machine learning within categories, blending separate rankings in All Product Search, NLP techniques used for matching queries and products.

4) Knowledge-based approach

Knowledge-based approach ranking typically conducted for a specific domain and may be involving experts to determine the rules to present more appropriate and accurate ranking results. Sorokina et al. [1] perform product ranking on Amazon e-commerce especially ranking in Fashion Store. The challenge is a discrepancy between what the majority of customers buy and what they want to see on top of the page. Assume consumers search "diamond ring" product. Commonly consumers bought cheap zirconium ring. However, if the search results show the zirconium ring as a first result, search results will be perceived as broken. The Fashion Store would look like a flea market, instead of a classic department store where the latest collections meet consumers at the entrance. This study set rules to solve this problem by identifying strategic categories of fashionable customers, customers who bought or added to cart fashion brand products significantly amplify their influence while designing the training set. 


\section{c. Dataset Characteristics}

In this section, we answer our third research question, RQ3. What are datasets characteristics for ranking a list of products? We identify the dataset of each primary studies by identifying the type of data and statistics, e.g., the number of domain and records.

We categorize the type of data to four categories: structured, e.g., relational; semi-structured, e.g., JSON, $\mathrm{XML}$; unstructured and graph. We found four studies using structured, four studies using semi-structured, ten studies using unstructured and three studies using graph type of data. We classify the number of the domain by the number of categories or product types in the dataset while the number of records shows the aggregate number of reviews, products, or other items presented in the dataset. Table 6 classifies primary studies by type of data and statistics of the dataset.

Table 5. Content-based Approach Studies Ranking Methods

\begin{tabular}{|c|c|c|c|c|}
\hline Code & Ranking item & Ranking summary & Ranking methods & Features used \\
\hline P3 & Review ranking & $\begin{array}{l}\text { Reviews and ratings are used to extract topic } \\
\text { distributions using LDA or word distributions using } \\
\text { LM. The ranking was computed by minimizing } \\
\text { Kullback-Leibler Divergence (KLD) with task- } \\
\text { specific target distributions. }\end{array}$ & $\begin{array}{l}\text { LDA/LM, summarization- } \\
\text { based, topic-based, rating- } \\
\text { based }\end{array}$ & Reviews, numeric ratings \\
\hline P5 & Product ranking & $\begin{array}{l}\text { The ranking method based on the sentiment analysis } \\
\text { technique (HowNet dictionary) and the intuitionistic } \\
\text { fuzzy set theory to rank the products through online } \\
\text { reviews }\end{array}$ & $\begin{array}{l}\text { Sentiment Analysis, Fuzzy set } \\
\text { theory }\end{array}$ & Reviews \\
\hline P7 & Product ranking & $\begin{array}{l}\text { Ranking products by combining weighted Q\&A } \\
\text { rank, weighted text-based review rank, and } \\
\text { normalized rank. }\end{array}$ & SVD-entropy, Bilinearity & $\begin{array}{l}\text { Reviews, Q\&A data, } \\
\text { rating of the reviews }\end{array}$ \\
\hline P8 & Product ranking & $\begin{array}{l}\text { Spearman's rank correlation coefficient-based opinion } \\
\text { ranking method is applied to rank the products based } \\
\text { on positive and negative ranks. }\end{array}$ & Spearman's rank correlation & Reviews \\
\hline P9 & Product ranking & $\begin{array}{l}\text { Ranking products by using similarity between the } \\
\text { search query arguments and the product ranking data } \\
\text { (product popularity) }\end{array}$ & $\begin{array}{l}\text { Content similarity, Product } \\
\text { popularity }\end{array}$ & Product data \\
\hline P11 & Aspect ranking & $\begin{array}{l}\text { Ranking aspect by exploiting the pros and cons of } \\
\text { reviews to improve aspect identification in free text } \\
\text { reviews. Then split the sentences and classify them } \\
\text { to the aspects of the product, then analyze using } \\
\text { sentiment classifier, then compute weight score for } \\
\text { each aspect to measure the importance and rank of } \\
\text { these aspects. }\end{array}$ & Sentiment analysis & Reviews \\
\hline P12 & Product ranking & $\begin{array}{l}\text { Ranking product by reviews' weight-based ranking } \\
\text { algorithm }\end{array}$ & Sentiment analysis & Reviews \\
\hline P13 & Aspect ranking & $\begin{array}{l}\text { Ranking aspect by combining sentiment } \\
\text { classification, aspect frequency, importance score, } \\
\text { and the rating score }\end{array}$ & Sentiment analysis & Reviews \\
\hline P14 & Aspect ranking & $\begin{array}{l}\text { Ranking aspect by employing aspect extraction using } \\
\text { sentiment analysis and aspect ranking using the } \\
\text { TOPSIS method }\end{array}$ & Sentiment analysis & Reviews \\
\hline
\end{tabular}




\begin{tabular}{|c|c|c|c|c|c|c|c|}
\hline Code & Ranking item & \multicolumn{3}{|c|}{ Ranking summary } & \multicolumn{2}{|c|}{ Ranking methods } & Features used \\
\hline P15 & Aspect ranking & \multicolumn{3}{|c|}{$\begin{array}{l}\text { Aspect ranking employs aspect extractor: POS } \\
\text { Tagging, Non-Aspect Removal, and sentiment score } \\
\text { predictor: Sentiment Dictionary (SD), Sentiment } \\
\text { Degree Dictionary (SDD), Negation Dictionary } \\
\text { (ND) }\end{array}$} & \multicolumn{2}{|l|}{ Sentiment analysis } & Reviews \\
\hline P16 & Product ranking & \multicolumn{3}{|c|}{$\begin{array}{l}\text { Product ranking employs efficient top-k algorithms } \\
\text { to rank items, by weighing each review's rating by its } \\
\text { relevance to the user query. }\end{array}$} & \multicolumn{2}{|l|}{ NRA-IRanker } & Reviews \\
\hline P17 & Product ranking & \multicolumn{3}{|c|}{$\begin{array}{l}\text { Ranking product by attributes, image pairs, and } \\
\text { categories with deep convolutional neural networks } \\
(\mathrm{CNNs})\end{array}$} & \multicolumn{2}{|c|}{$\begin{array}{l}\text { Convolutional Neural } \\
\text { Networks }\end{array}$} & Product image \\
\hline P18 & Product ranking & \multicolumn{3}{|c|}{ Ranking product by aspect polarity identification } & \multicolumn{2}{|l|}{ Sentiment Analysis } & Reviews \\
\hline P19 & Product ranking & \multicolumn{3}{|c|}{$\begin{array}{l}\text { Ranking product by combining review ranking, } \\
\text { aspect weighting, and brand ranking to produce } \\
\text { unified product ranking }\end{array}$} & \multicolumn{2}{|c|}{$\begin{array}{l}\text { Sentiment Analysis, aspect } \\
\text { weighting, brand ranking, } \\
\text { review usefulness }\end{array}$} & Reviews \\
\hline P20 & Product ranking & \multicolumn{3}{|c|}{$\begin{array}{l}\text { Product ranking conducted by using twin-bipartite } \\
\text { graph model to catch the review and ranking } \\
\text { relationship among users, products, and shops. }\end{array}$} & \multicolumn{2}{|l|}{ Custom formulation } & Reviews, ratings \\
\hline $\mathrm{P} 21$ & Product ranking & \multicolumn{3}{|c|}{$\begin{array}{l}\text { Ranking by using Graph-based ordering algorithms } \\
\text { to present a novel hierarchical aspect-based product } \\
\text { ranking approach }\end{array}$} & \multicolumn{2}{|c|}{$\begin{array}{l}\text { Graph-based ordering } \\
\text { algorithm }\end{array}$} & Reviews \\
\hline $\mathrm{P} 22$ & Product ranking & \multicolumn{3}{|c|}{$\begin{array}{l}\text { Ranking by calculating stochastic dominance degrees } \\
\text { and ranking the candidate products using the } \\
\text { PROMETHEE-II method. }\end{array}$} & \multicolumn{2}{|c|}{$\begin{array}{l}\text { Stochastic dominance rules, } \\
\text { PROMETHEE-II method }\end{array}$} & Product attributes \\
\hline Code & \multicolumn{2}{|l|}{ Source } & Type of data & \multicolumn{2}{|c|}{ Number of categories } & \multicolumn{2}{|c|}{ Number of items in the dataset } \\
\hline $\mathrm{P} 1$ & Amazon & & Unspecified & \multicolumn{2}{|c|}{ Whole Amazon categories } & \multicolumn{2}{|c|}{ Unspecified } \\
\hline $\mathrm{P} 2$ & MovieLens & & Unstructured & \multicolumn{2}{|l|}{1 (Movies) } & \multicolumn{2}{|c|}{$\begin{array}{l}1,000,209 \text { movie ratings from } 6,040 \\
\text { users on } 3,706 \text { movie items }\end{array}$} \\
\hline $\mathrm{P} 3$ & Epinions & & Unstructured & \multicolumn{2}{|c|}{$\begin{array}{l}4 \text { (America West Airlines, Pokemon Snap } \\
\text { for Nintendo 64, Starbucks, Microsoft } \\
\text { Windows ME) }\end{array}$} & \multicolumn{2}{|c|}{$\begin{array}{l}\text { More than } 300 \text { products, } \\
\text { with over } 200,000 \text { reviews }\end{array}$} \\
\hline $\mathrm{P} 4$ & zol.com.cn & & Unstructured & \multicolumn{2}{|c|}{$\begin{array}{l}3 \text { (Mobile phones, laptops, digital } \\
\text { camera) }\end{array}$} & \multicolumn{2}{|c|}{500 product reviews } \\
\hline P5 & $\begin{array}{l}\text { Automobile Hom } \\
\text { PCAuto }\end{array}$ & & Unstructured & \multicolumn{2}{|c|}{1 (Automobile products) } & \multicolumn{2}{|c|}{1679 reviews } \\
\hline P6 & Amazon & & Graph & \multicolumn{2}{|c|}{$\begin{array}{l}3 \text { (Energy-saving Lamp, Hotel Room, } \\
\text { Washing Machine) }\end{array}$} & 140 pro & \\
\hline P7 & Amazon & & Semi-structured & $\begin{array}{l}3 \text { (Musical Instrumen } \\
\text { Health, and Personal }\end{array}$ & $\begin{array}{l}\text { ts, Electronics, } \\
\text { Care) }\end{array}$ & $1500 \mathrm{pr}$ & ucts \\
\hline P8 & OpinRank & & Semi-structured & 1 (Car) & & 611 revi & \\
\hline P9 & Unspecified & & Unspecified & Unspecified & & Unspeci & \\
\hline P10 & Doctors, Amazon & & Semi-structured & Unspecified & & Unspeci & \\
\hline P11 & $\begin{array}{l}\text { cnet.com, viewpo } \\
\text { reevoo.com, gsma } \\
\text { com, and pricegra } \\
\text { com }\end{array}$ & $\begin{array}{l}\text { ints.com, } \\
\text { irena. } \\
\text { abber. }\end{array}$ & Unstructured & $\begin{array}{l}8 \text { (Camera, Laptop, } \\
\text { Camcorder, TV, GPS }\end{array}$ & $\begin{array}{l}\text { MP3, Phone, } \\
\text {, Printer) }\end{array}$ & $\begin{array}{l}94,560 \\
\text { product }\end{array}$ & nsumer reviews on 21 \\
\hline P12 & Unspecified & & Semi-structured & 1 (Digital Camera) & & $8746 \mathrm{pr}$ & ucts \\
\hline P13 & Amazon and Cnet & & Structured & $\begin{array}{l}6 \text { (Camera, Mobile, } \\
\text { MP3 Player, DVD Pl }\end{array}$ & $\begin{array}{l}\text { Router, Antivirus, } \\
\text { layer) }\end{array}$ & 14 prod & ts reviews \\
\hline P14 & Bing Liu & & Unstructured & $\begin{array}{l}3 \text { (Digital Camera, C } \\
\text { Player) }\end{array}$ & ell Phone, MP3 & $1302 \mathrm{re}$ & \\
\hline P15 & Amazon.in & & Unstructured & 1 (Mobile Phone) & & $3000 \mathrm{re}$ & \\
\hline
\end{tabular}




\begin{tabular}{|c|c|c|c|c|}
\hline Code & Source & Type of data & Number of categories & Number of items in the dataset \\
\hline P16 & Doctors and Amazon & Unstructured & 4 (Healthcare, Books, Clothing, Movies) & $\begin{array}{l}\text { Doctors } 248580 \text { items } 726996 \text { reviews } \\
\text { Amazon } 9743974 \text { items } 82037337 \\
\text { reviews }\end{array}$ \\
\hline P17 & DeepFashion, Alibaba & Unstructured & $\begin{array}{l}5 \text { (Fashion, Clothes, Snacks, Beauty, } \\
\text { Furniture) }\end{array}$ & $\begin{array}{l}\text { DeepFashion 8,471 items } \\
\text { Alibaba } 400 \text { items }\end{array}$ \\
\hline P18 & review.net & Structured & Unspecified & Unspecified \\
\hline P19 & Amazon & Structured & 2 (HDTVs and Cameras) & $\begin{array}{l}197 \text { products and } 56,368 \\
\text { Reviews }\end{array}$ \\
\hline $\mathrm{P} 20$ & Taobao & Graph & 15 (Clothes and Shoes, Books, etc.) & $\begin{array}{l}553,000 \text { customers, } 300,000 \\
\text { products, 10,000 shops and } 924,000 \\
\text { reviews }\end{array}$ \\
\hline $\mathrm{P} 21$ & $\begin{array}{l}\text { CNet, Amazon, Reevoo, } \\
\text { Gsmarena }\end{array}$ & Graph & 2 (Mobile Phone, MP3 Players) & $\begin{array}{l}\text { Six mobile phone reviews, five mp3 } \\
\text { players reviews }\end{array}$ \\
\hline $\mathrm{P} 22$ & $\begin{array}{l}\text { Autohome (autohome. } \\
\text { com.cn) }\end{array}$ & Unstructured & 1 (Automobile) & 7322 reviews \\
\hline
\end{tabular}

\section{Discussion}

In this section, we discuss our general observation to find open issues or new gaps in the literature. We start finding issues or new gaps by identifying our findings based on our research question answers.

As the answer to RQ1: "What are the existing ranking items for product ranking?", We identify the majority of the existing ranking item is "product ranking", followed by "aspect ranking". But only one study perform "review ranking". It indicates the "review ranking" is a valuable research topic area. Besides, Electronic Word of Mouth (e-WOM) products massive data in product reviews, not only in the form of text reviews and numeric ratings but also pictures of the product. This plays an essential role to determine how to rank the reviews better, such as usefulness, recency or relevancy for a particular aspect or whole aspects.

As the answer to RQ2: "What are the current approaches for product ranking?", We identify the majority of ranking approach is the content-based approach, followed by one study of each collaborative filtering, hybrid-based and knowledge-based approach. Although content-based is a majority, combining other methods may result in the better product ranking. Thus, different approaches are valuable research topic area for a specific case study. For example, by adding a knowledge-based and hybrid-based approach may provide more relevant product ranking in a particular area, e.g., halal product ranking [26]. It is crucial to add a knowledge-based approach such as make higher ranking to the product which has a halal certificate to indicate the safe product guarantee for Muslim.

As the answer to RQ3: "What are datasets characteristics for ranking a list of products?", We identify the majority type of data is unstructured, followed by semi-structured, structured and graph. In the majority, the studies conduct product ranking using sentiment analysis, except the study which uses a graph. Commonly, the graph uses different approaches to rank the products such as product centrality to calculate the product score to indicate product popularity. Also, product attributes and connection strength of edges also contribute to producing a higher score. Example of the type data as a semi-structured and able to model as a graph is Resource Description Framework (RDF). RDF contains a subject, predicate, and object to present a fact. Based on all of the studies, no one conduct product ranking use RDF as a source of the type of data and model as a graph. Thus, it is a valuable research topic area.

\section{Conclusion}

We presented a systematic literature review of empirical studies on product ranking methods. We present 22 studies describing various product ranking methods in various case studies.

The identified primary studies are research articles which experiment certain case studies. More than half published in the journal and the rest at the conference.

The ranking items of product ranking are classified into three of ranking item types: product ranking, aspect ranking, and review ranking. The existing approaches for product ranking classified into four categories: collaborative filtering, content-based, hybrid-based, and knowledge-based. The dataset characteristics type of data in the majority are unstructured, followed by semistructured, structured and graph.

As future research topics, we suggest conducting product ranking in case studies of product ranking or review ranking. Then perform a knowledge-based or hybrid-based approach for a better product ranking. Then do product ranking using a semi-structured type of data and modeling as a graph.

\section{Acknowledgment}

This research is being conducted and was supported by funding from Lembaga Penelitian dan Pengabdian kepada Masyarakat, Institut Teknologi Sepuluh Nopember (LPPM - ITS) and Kementerian Riset, Teknologi, dan 
Pendidikan Tinggi (or Ministry of Higher Education Indonesia) with the scheme of Postgraduate Research number 1168/PKS/ITS/2019.

\section{References}

[1] D. Sorokina and E. Cantú-paz, "Amazon Search : The Joy of Ranking Products," Proc. 39th Int. ACM SIGIR Conf. Res. Dev. Inf. Retr., 2016.

[2] Yin-Fu Huang and Heng Lin, "Web product ranking using opinion mining," in 2013 IEEE Symposium on Computational Intelligence and Data Mining (CIDM), 2013, pp. 184-190.

[3] B. B. Alengadan and S. S. Khan, "Modified aspect/ feature based opinion mining for a product ranking system," in 2018 IEEE International Conference on Current Trends in Advanced Computing (ICCTAC), 2018, pp. 1-5.

[4] Y. Liu, J. W. Bi, and Z. P. Fan, "Ranking products through online reviews: A method based on sentiment analysis technique and intuitionistic fuzzy set theory," Inf. Fusion, 2017.

[5] A. K. J and S. Abirami, "Aspect-based opinion ranking framework for product reviews using a Spearman's rank correlation coefficient method," Inf. Sci. (Ny)., 2018.

[6] E. Najmi, K. Hashmi, Z. Malik, A. Rezgui, and H. U. Khan, "CAPRA: a comprehensive approach to product ranking using customer reviews," Computing, 2015.

[7] R. Krestel and N. Dokoohaki, "Diversifying customer review rankings," Neural Networks, vol. 66, pp. 36-45, Jun. 2015.

[8] M. Scholz, J. Pfeiffer, and F. Rothlauf, "Using PageRank for non-personalized default rankings in dynamic markets,” Eur. J. Oper. Res., 2017.

[9] B. Kitchenham and S. Charters, "Guidelines for performing Systematic Literature reviews in Software Engineering Version 2.3," Engineering, 2007.

[10] M. Zhang, X. Guo, and G. Chen, "Prediction uncertainty in collaborative filtering: Enhancing personalized online product ranking," Decis. Support Syst., 2016.

[11] R. Krestel and N. Dokoohaki, "Diversifying customer review rankings," Neural Networks, 2015.

[12] X. Yang, G. Yang, and J. Wu, "Integrating rich and heterogeneous information to design a ranking system for multiple products," Decis. Support Syst., 2016.

[13] C. L. Sabharwal and B. Anjum, "An SVD-Entropy and bilinearity based product ranking algorithm using heterogeneous data," J. Vis. Lang. Comput., 2017.

[14] G. Kaur and R. Bhatia, "Semantic Product Ranking Model (SePRaM) using PNN over the Heuristic Product Data," Int. J. Comput. Appl., 2016.

[15] Zheng-Jun Zha, Jianxing Yu, Jinhui Tang, Meng Wang, and Tat-Seng Chua, "Product Aspect Ranking and Its Applications," IEEE Trans. Knowl. Data Eng., vol. 26, no. 5, pp. 1211-1224, May 2014.

[16] M. Arun Manicka Raja, S. G. Winster, R. Saravanan, and S. Swamynathan, "ProRankSys: Ranking consumer products by predicting opinion's weight on reviews," in Proceedings of IEEE International Conference on Computer Communication and Systems ICCCS14, 2014, pp. 033-038.

[17] N. R. Bhamre and N. N. Patil, "Aspect rating analysis based product ranking," in 2016 International Conference on Global Trends in Signal Processing, Information Computing and Communication (ICGTSPICC), 2016, pp. 197202.

[18] S. A. A. A. Alrababah, K. H. Gan, and T.-P. Tan, "Product aspect ranking using sentiment analysis and TOPSIS," in 2016 Third International Conference on Information Retrieval and Knowledge Management (CAMP), 2016, pp. 13-19.

[19] T. Sangeetha, N. Balaganesh, and K. Muneeswaran, "Aspects based opinion mining from online reviews for product recommendation," in 2017 International Conference on Computational Intelligence in Data Science(ICCIDS), 2017, pp. $1-6$.

[20] M. Shahbazi, M. Wiley, and V. Hristidis, "IRanker: Query-specific ranking of reviewed items," in Proceedings - International Conference on Data Engineering, 2017.

[21] Y. H. Kuo and W. H. Hsu, "Feature Learning with Rank-Based Candidate Selection for Product Search," in Proceedings - 2017 IEEE International Conference on Computer Vision Workshops, ICCVW 2017, 2018.

[22] R. Zhang, M. Gao, X. He, and A. Zhou, "Learning user credibility for product ranking," Knowl. Inf. Syst., 2016.

[23] S. Li, Z. Ming, Y. Leng, and J. Guo, "Product ranking using hierarchical aspect structures," J. Intell. Inf. Syst., 2017.

[24] Z. P. Fan, Y. Xi, and Y. Liu, "Supporting consumer's purchase decision: a method for ranking products 
based on online multi-attribute product ratings," Soft Comput., 2018.

[25] J. S. J. Breese, D. Heckerman, and C. Kadie, "Empirical analysis of predictive algorithms for collaborative filtering," Proc. 14th Conf. Uncertain.
Artif. Intell., 1998.

[26] N. A. Rakhmawati, J. Fatawi, A. C. Najib, and A. A. Firmansyah, "Linked open data for halal food products," J. King Saud Univ. - Comput. Inf. Sci., 2019. 